Archimer, archive institutionnelle de l'Ifremer

\title{
Effects of exposure to petroleum hydrocarbons upon the metabolism of the common sole Solea solea
}

\author{
Fariba Davoodi ${ }^{\mathrm{a}}$ and Guy Claireaux ${ }^{\mathrm{b},{ }^{*}}$ \\ ${ }^{a}$ Centre de Recherche sur les Ecosystèmes Littoraux Anthropisés (CNRS-IFREMER-ULR), Place du Séminaire, \\ 17137 L'Houmeau, France \\ b Institut des Sciences de l'Evolution de Montpellier, Station Méditerranéenne de L'Environnement Littoral, 1 Quai \\ de la Daurade, 34200 Sète, France \\ *: Corresponding author : guy.claireaux@univ-montp2.fr
}

\begin{abstract}
:
On December 12th, 1999, the oil tanker Erika sank off the southern coast of Brittany (France), releasing 20 000-30 000 tons of heavy oil in the open sea. Among the affected coastal habitats were important nurseries for numerous flatfish species and particularly for the common sole, Solea solea. To investigate the potential impact of the spill on this economically significant resource, we employed Fry's concept of metabolic scope for activity to assess the deleterious effect of fuel exposure on the functional integrity of juvenile sole. Fish were captured from uncontaminated areas and experimentally exposed to contamination conditions mimicking those encountered during the weeks that followed the Erika spill. Using respirometry techniques we measured basal and active metabolic rates, and calculated aerobic metabolic scope, in control and fuel-exposed sole. We then compared the ability of control and fuel-exposed sole to face an episode of reduced oxygen availability. We found that whereas basal metabolic rate was not altered in fuel-exposed fish, active metabolic rate $(-27 \%)$, and therefore aerobic metabolic scope, were impacted. These changes in metabolic scope were viewed as indicating changes in fishes' ability to face environmental contingencies. Finally the ability of sole to face an episode of reduced oxygen availability was found to be significantly altered following fuel exposure as indicated by a $65 \%$ increase in the critical oxygen level. It is concluded that fuel-exposed sole are functionally impaired and less able to face environmental challenges. The link between these results and the recently reported fall in the abundance of the year class that suffered the Erika oil spill is discussed.
\end{abstract}

Keywords: Erika oil spill; Fuel exposure; Metabolism; Environmental adaptation; Solea solea 


\section{INTRODUCTION}

Bioenergetics investigates how energy acquired in food is either dissipated in metabolic processes, retained as new body tissue (somatic or gonadal growth), or lost as waste. Bioenergetics therefore provides a unique view point of the interactions between organisms and their environment based upon how they partition energetic resources as a function of environmental contingencies (Jobling, 1993; Webber et al., 1998). Because they influence energy acquisition and use, environmental factors largely contribute to shape the adaptive strategy of living organisms, with potential consequences for population dynamics and ecosystem productivity (Neill et al., 1994). In fish, a large number of studies have investigated the effects of environmental variability upon the activities and performance of individuals. Yet our current ability to predict the influence of environmental contingencies at population level remains limited (Kerr, 1990; Neill et al., 1994; van der Veer et al., 2000). Among the missing pieces of information is a set of functional relationships linking environmental conditions, bioenergetics and individuals' fitness. Fry $(1947,1971)$ proposed a conceptual framework to analyse the reaction norm linking environmental conditions and fish performance. At the basis of this concept is the notion of metabolic scope for activity and its use as a metric of one organism's ability to cope with environmental demands. In operational terms, the metabolic scope for activity measures, in units of energy dissipation, the difference between the active metabolic rate (the maximal energetic power available for discretionary activities) and the standard metabolic rate (the minimum metabolic rate necessary to sustain mandatory activities). Note that in Fry's conception, activities include not only mechanical work (e.g., swimming) but also costs of growth (somatic or gonadic) or costs of regulating the internal milieu (homeostasis).

On December $12^{\text {th }}, 1999$, the oil tanker Erika sank off the southern coast of Brittany (France), releasing 20 000-30 $000 \mathrm{t}$ of heavy oil in the open sea. The weather conditions and currents in the vicinity of the spill caused the pollution to spread throughout the Bay of Biscay. Moreover, the hurricane Lothar that occurred on December $28-29^{\text {th }}$ precipitated the beaching of the oil, impacting nearly $500 \mathrm{~km}$ of coast-line from the South headland of Brittany to the North of Oléron Island. Among the affected coastal habitats were important nurseries for numerous flatfish species and particularly for the common sole, Solea solea (Koutsikopoulos et al., 1989). In the Bay of Biscay, the common sole is a species of high commercial value with 1795 tons harvested yearly for a total value of 17.7 million euros (Léauté and Caill-Milly, 2003). Adult soles spawn off-shore during the first three months of the year, with a peak in early March in North Biscay. As they drift in-shore, pelagic eggs and larvae transform into juvenile benthic fish which concentrate in shallow waters and estuaries in June and July. Juveniles remain on coastal nurseries for 2 to 3 years until they reach maturity and migrate to deeper waters.

To investigate the potential impact of the ERIKA oil spill on this economically significant resource, the current study employed Fry's concept of metabolic scope for activity to assess the deleterious effect of fuel exposure on the functional integrity of juvenile sole. Fish were captured from uncontaminated areas and experimentally exposed to contamination conditions mimicking those encountered during the weeks that followed the ERIKA spill. Using respirometry techniques we measured basal and active metabolic rates, and calculated aerobic metabolic scope, in control and fuel-exposed sole. We then compared the ability of control and fuel-exposed sole to face a recurrent environmental challenge in coastal ecosystems, namely an episode of reduced oxygen availability.

\section{MATERIALS AND METHODS}

\section{Experimental animals}

Juvenile soles were collected by trawling a region of muddy substrate in the Pertuis Breton North of Ré Island (Long $1^{\circ} 20^{\prime}$; Lat $\left.46^{\circ} 12^{\prime}\right)$. Upon arrival at the laboratory, fish were transferred to indoor rearing tanks $(2 \times 2 \mathrm{~m})$ and submitted to a 7-day sanitary antibiotic treatment. The tanks were supplied with open flow seawater at ambient temperature and salinity $\left(15-16{ }^{\circ} \mathrm{C}\right.$ and $31-33 \%$ respectively). Fish were then allowed a further 4-week period of acclimation to the prevailing conditions, during which they were fed with fresh mussels and oysters. 


\section{Contamination protocol}

Following acclimation, animals were randomly allocated to two experimental groups. Group 1 consisted of 10 fish $(0.115 \pm 0.009 \mathrm{~kg})$ and group 2 of 8 fish $(0.146 \pm 0.029 \mathrm{~kg})$. Group 1 was used as a contamination-free control whereas fish from group 2 were exposed to fuel.

Fish from group 2 were successively submitted to the following contamination protocol. Before being exposed to fuel, fish were unfed for $24 \mathrm{~h}$. Exposure to fuel was performed in $500 \mathrm{~L}$ thermostated ( 15 ${ }^{\circ} \mathrm{C}$ ) rearing tanks covered with a polyethylene lining, topped with $2 \mathrm{~cm}$ of sand. Typically exposition lasted 5 days and two fish were exposed simultaneously. During that whole period, the water was not renewed and fish were not fed. The required fuel to water ratios $(1 / 200 \mathrm{vol} / \mathrm{vol})$ was obtained by adding fuel directly onto the surface of the experimental tank. Gentle aeration of the water ensured homogeneity of the soluble phase. There was no direct contact between fish in the sand and the fuel floating at the surface, although the presence of micro-particles in the water column cannot be totally dismissed. At the time when these experiments were initiated, the original fuel from the tanker ERIKA was no longer available and a heavy fuel $n^{\circ} 2$ was used as a substitute. The polycyclic aromatic hydrocarbon (PAH) composition of these two fuels was comparable when assessed as described by Mazéas and Budzinski (2001). Differences were noticed, however, particularly with regard to longchain PAH (see Claireaux et al. 2004 for a comparison of the PAH composition of these fuels) suggesting that fuel from Erika was actually more toxic than fuel $n^{\circ} 2$.

In our contamination conditions, white muscle PAH concentration were found to be $92 \mathrm{ng} \mathrm{g}^{-1}$ (Claireaux et al., 2004). Although higher, this value is consistent with the field observations (10 - $30 \mathrm{ng}$ $\mathrm{g}^{-1}$ ) that were made during the months that followed the spill (Claireaux et al. 2004; Budzinski et al. 2004; Tronczynski et al. 2004). This relative consistency is particularly remarkable when one considers that fish are liable to metabolized PAH (Budzinski et al. 2004). Consequently, we regarded our fuel exposure protocol as appropriately replicating the contamination conditions of enclosed sites such as a cove or a river mouth. One restriction must be acknowledged, however. After the Erika oil spillage, the concentrations of dissolved and particulate PAH displayed changes in the composition pattern of different suites of PAH (Tronczynski et al. 2004). These changes are characteristic of weathered fuel-oil but they could not be replicated in the current experiment. Likewise, biodegradability of the Erika oil was found to be low (Oudot 2000; Bordenave et al. 2004) and therefore was not taken into consideration when designing the contamination protocol.

Following the 5-day contamination period, fish were transferred to a tank containing unpolluted water and were left undisturbed for 2-5 hours before being introduced into the respirometry set-up. Control fish were submitted to the same manipulation protocol but were not exposed to contaminated water.

\section{Respirometry}

Fish were anaesthetised in a solution of ethyl-m-aminobenzoate (MS-222, $100 \mathrm{mg} \mathrm{L}^{-1}$ ), weighed and introduced in a $6.5 \mathrm{I}$ respirometry chamber where they remained during four to five days. During that period, standard metabolic rate (day 1 to 2 ) active metabolic rate (day 3 ) and tolerance to hypoxia (day 4) were determined. The experimental set up and the oxygen consumption $\left(\mathrm{MO}_{2}\right)$ measurement protocol were essentially similar to those described in Lefrançois and Claireaux (2003). Briefly, the respirometers were placed in a larger tank which contained thermoregulated water $\left(15^{\circ} \mathrm{C}\right)$. Water oxygenation was regulated via a counter-current gas equilibration column placed up stream from the respirometer and bubbled with air, under control conditions, or with nitrogen to induce hypoxia. The respirometers were supplied with water from the outer tank at a flow rate of 2-3 $\mathrm{L} \mathrm{min}^{-1}$ via a pump connected to a timer. Oxygen concentration in the respirometers was measured using oxygen probes (Orbisphere Laboratories 27141) connected to a multichannel oxygen measuring system (Orbishere Laboratories 2610) and a computer. Two specifically dedicated pumps ensured water homogenisation inside the respirometers. Oxygen probes were calibrated daily. Determination of oxygen consumption was carried out after turning off the pump controlling water supply to the respirometers. This pump was turned off automatically for $15 \mathrm{~min}$ and the water oxygen concentration $\mathrm{C}_{\mathrm{w}} \mathrm{O}_{2}$ was continuously recorded. In order to ensure an appropriate equilibrium between fish oxygen demand and the time lag of the experimental set-up, only the last half of each 15-minute oxygen monitoring periods was used to calculate oxygen consumption.

\section{Standard metabolic rate}

During the first two days of each experimental series fish were left undisturbed and measurements of oxygen consumption were carried out automatically (15 min every $30 \mathrm{~min}$ ) to estimate standard 
metabolic rate (SMR) in normoxic conditions. For each fish, SMR was estimated as the mean of the lower 0.1 quantile of $\mathrm{MO}_{2}$. Fish periodically exhibited activity during respiratory trials. Using the $10 \%$ quantile of $\mathrm{MO}_{2}$ as an estimate of SMR reliably removed from the data set these activity-induced elevations in metabolism. This procedure was performed with a custom-designed program within Rsoftware (Denis Chabot, Maurice Lamontagne Institute, Mont-Joli Qc, Canada).

\section{Active metabolic rate}

On the third day, AMR was estimated using the following procedure. Respirometer chambers were opened and fish were transferred to a small tank where they were forced to swim until exhaustion (approx $10 \mathrm{~min}$ ). Fish were then rapidly transferred back into the respirometer chambers, which were then closed. The monitoring of oxygen consumption was immediately started using the automatic procedure described above except that the $\mathrm{O}_{2}$ monitoring time was reduced to $7 \mathrm{~min}$ and the flushing time to $2 \mathrm{~min}$. After three successive determinations of $\mathrm{MO}_{2}$, the mean of the highest two values was taken to represent AMR.

\section{Hypoxia}

During day 4, fish were exposed to a 5-6 h progressive hypoxia to determine the critical $\mathrm{O}_{2}$ level $\left(\mathrm{O}_{2 \text { crit }}\right)$, the minimum water oxygen concentration required to sustain SMR. In order to assess $\mathrm{O}_{2 \text { crit }}$, water oxygenation was reduced in a stepwise manner by bubbling nitrogen in the gas equilibration column situated upstream from the respirometers. Water oxygenation steps were $20 \%$ air saturation apart and the lowest level reached was $20 \%$ air saturation. At each $\mathrm{O}_{2}$ step, the pump controlling the water supply to the respirometers was turned off and the water oxygen concentration continuously recorded for the next $15 \mathrm{~min}$. Following $\mathrm{MO}_{2}$ determination at the lowest oxygenation level, normoxic conditions were rapidly restored (within $15 \mathrm{~min}$ ).

\section{Calculations}

Oxygen consumption ( $\mathrm{mg} \mathrm{O}_{2} \mathrm{~kg}^{-1} \mathrm{~h}^{-1}$ ) was calculated using the following formula:

$$
M O_{2}=\Delta C_{w} O_{2} \times \Delta t^{-1} \times V O L_{\text {resp }} \times M^{-1}
$$

where $\Delta \mathrm{C}_{\mathrm{w}} \mathrm{O}_{2}$ is the change in water oxygen concentration $\left(\mathrm{mg} \mathrm{O}_{2} \mathrm{~L}^{-1}\right)$ during $\Delta t$ the measuring time (h), $V O L_{\text {resp }}$ is the volume of the respirometer minus the volume of the fish (I), and $M$ is the mass of the fish (kg). Routine oxygen consumption was standardised to a body mass of $100 \mathrm{~g}$ using an allometric exponent of 0.8 (Van den Thillart et al., 1994). Background oxygen consumption by microorganisms was routinely assessed before the fish was transferred into the chamber by recording the oxygen consumption of an empty respirometer.

In order to determine the critical water oxygen concentration $\left(\mathrm{O}_{2 \text { crit }}\right)$, the relation between $M \mathrm{O}_{2}$ and ambient $\mathrm{O}_{2}$ was modelled for each fish group using the following equation:

$$
M \mathrm{O}_{2}=\mathrm{a} \log \mathrm{O}_{2}+\mathrm{b} .
$$

The $\mathrm{O}_{2}$ level for which $\mathrm{MO}_{2}$ equals $S M R$ corresponds to $\mathrm{O}_{2 \text { crit. }}$

\section{Data analysis and statistics}

Statistical analyses were conducted using STATGRAPHIC PLUS version 5.1. In order to check normality of distribution and homogeneity of variances, Grubbs test and Dixon test were applied prior to ANOVA. The effect of fuel exposure and water oxygen content on fish oxygen consumption was estimated using multi-way ANOVA followed by a posteriori tukey test. The oxygen consumption in each group of fish was tested using One-way ANOVA. A $t$-test was then used for comparison of means of SMR and AMR in control and contaminated fish (with $\alpha=0.05$ ). Throughout the text data are presented as means \pm SEM. 


\section{RESULTS}

\section{Metabolic rates and aerobic scope}

Standard metabolic rate of control and contaminated fish groups are presented in Fig. 1. The mean SMR in control and contaminated fish was $39.2 \pm 4.5$ and $31.6 \pm 3.4 \mathrm{mg} \mathrm{O}_{2} \mathrm{~kg}^{-1} \mathrm{~h}^{-1}$, respectively. These values were not found significantly different $(p=0.23)$. The mean values for AMR of control and contaminated fish were $125.8 \pm 11.3$ and $91.9 \pm 9.8 \mathrm{mg} \mathrm{O}_{2} \mathrm{~kg}^{-1} \mathrm{~h}^{-1}$ respectively, and the difference was found statistically significant $(p<0.05$; Fig. 2). As a consequence of their reduced AMR, the calculated metabolic scope (MS) was nearly significantly lower $(-30 \%)$ in fuel-exposed $(60.2 \pm 8.8 \mathrm{mg}$ $\left.\mathrm{O}_{2} \mathrm{~kg}^{-1} \mathrm{~h}^{-1}\right)$ than in control individuals $\left(85.7 \pm 11.6 \mathrm{mg} \mathrm{O}_{2} \mathrm{~kg}^{-1} \mathrm{~h}^{-1}\right)$.

\section{Effect of reduced water oxygenation}

Throughout the hypoxic episode, control fish displayed significantly higher levels of oxygen consumption than contaminated fish, but the pattern of change of the metabolic demand with water oxygen concentration was similar in both groups (Fig. 2).

Parameter estimations for modelling the relationships between $\mathrm{MO}_{2}$ and ambient $\mathrm{O}_{2}$, are given in Table 1. Based on these equations we found a marked difference in the value of $\mathrm{O}_{2 \text { crit }}$ between the two groups. The $\mathrm{O}_{2 \text { crit }}$ in fuel-exposed fish $\left(4.1 \mathrm{mg} \mathrm{O}_{2} \mathrm{~L}^{-1}\right)$ was markedly higher than the value measured in the control animals $\left(2.5 \mathrm{mg} \mathrm{O}_{2} \mathrm{~L}^{-1}\right)$.

\section{DISCUSSION}

The objective of the present experiment was to investigate the effect of exposure to petroleum hydrocarbons upon metabolism of the common sole. We found that whereas basal metabolic rate was not altered in fuel-exposed fish, active metabolic rate and therefore aerobic metabolic scope were impacted. These changes in metabolic scope were viewed as indicating changes in fishes' ability to face environmental contingencies. Accordingly, the ability of sole to face an episode of reduced oxygen availability was found to be significantly impaired following fuel exposure.

Our measurements of metabolism in control, uncontaminated individuals are generally consistent with those reported in the literature. The SMR of unpolluted sole acclimated to $15^{\circ} \mathrm{C}$ was $39.2 \mathrm{mg} \mathrm{O}_{2} \mathrm{~kg}^{-1}$ $\mathrm{h}^{-1}$ in the current study, a value in good agreement with the SMR of $33.7 \mathrm{mg} \mathrm{O}_{2} \mathrm{~kg}^{-1} \mathrm{~h}^{-1}$ reported by Lefrançois and Claireaux (2003) for $100 \mathrm{~g}$ individuals at the same temperature. Our result is also in agreement with that of van den Thillart et al. (1994), who reported an SMR of $41.0 \mathrm{mgO}_{2} \mathrm{~kg}^{-1} \mathrm{~h}^{-1}$ for a $100 \mathrm{~g} \mathrm{common}$ sole at $20^{\circ} \mathrm{C}$. This value is also within the range of values reported for other flatfish species. Duthie (1982) estimated SMR of $230-400 \mathrm{~g}, 15^{\circ} \mathrm{C}$ acclimated flounder (Platichthys flesus), common dab (Limanda limanda) and lemon sole (Microstomus kitt) to be $36.7,41.8$ and $51.8 \mathrm{mg} \mathrm{O}$ $\mathrm{kg}^{-1} \mathrm{~h}^{-1}$ respectively.

Our value for $A M R$ in control sole $\left(125.8 \mathrm{mg} \mathrm{O}_{2} \mathrm{~kg}^{-1} \mathrm{~h}^{-1}\right)$ is also in agreement with the value reported by Lefrançois and Claireaux (2003), who estimated the AMR of a $100 \mathrm{~g}$ common sole to be approximately $139.0 \mathrm{mg} \mathrm{O}_{2} \mathrm{~kg}^{-1} \mathrm{~h}^{-1}$ at $15^{\circ} \mathrm{C}$. Van den Thillart et al. (1994) reported an AMR of 152.2 $\mathrm{mg} \mathrm{O}_{2} \mathrm{~kg}^{-1} \mathrm{~h}^{-1}$ at $20^{\circ} \mathrm{C}$. Our estimate of AMR in sole is also comparable to AMR values reported by Duthie (1982) in flounder, common dab and lemon sole i.e., 215.0, 164.6 and $171.4 \mathrm{mg} \mathrm{O}_{2} \mathrm{~kg}^{-1} \mathrm{~h}^{-1}$ respectively at $15{ }^{\circ} \mathrm{C}$. Mallekh and Lagardère (2002) reported the AMR of turbot (Scophthalmus maximus) to be $177.0 \mathrm{mg} \mathrm{O}_{2} \mathrm{~kg}^{-1} \mathrm{~h}^{-1}$ at $14{ }^{\circ} \mathrm{C}$.

Metabolic scope of uncontaminated sole was estimated to be $85.7 \mathrm{mg} \mathrm{O}_{2} \mathrm{~kg}^{-1} \mathrm{~h}^{-1}$. This value is slightly lower than the value reported for the same species by Lefrançois and Claireaux (2003) i.e., $105.3 \mathrm{mg}$ $\mathrm{O}_{2} \mathrm{~kg}^{-1} \mathrm{~h}^{-1}$ at $15^{\circ} \mathrm{C}$.

Standard metabolic rate in fuel-exposed fish was not significantly different from that of control fish, suggesting that the animals were able to meet the demands of their minimal life sustaining metabolic processes. However, the active metabolic rate of fuel-exposed fish was lower than that of control fish (- $27 \%)$, suggesting an alteration in the ability of fish to mobilize energy when faced with high metabolic demand. 
Parallel experiments where fish were exposed to similar contamination conditions before being transferred to semi-natural mesocosms (Claireaux et al., 2004) support this hypothesis of altered metabolic performance and, therefore, of reduced adaptive flexibility, in contaminated individuals. These experiments revealed that 6 months after an experimental exposure to fuel, only $33 \%$ of the contaminated fish were still alive. Under the same conditions the survival of the uncontaminated group was $54 \%$. Growth rate was also impaired in fuel exposed fish. Whereas the initial length was similar in both groups $(7.9 \mathrm{~cm})$, the final size was $12.3 \mathrm{~cm}$ in the control group and $10.8 \mathrm{~cm}$ in the fuel-exposed group. Accordingly, mean otolith growth was $4.1 \mu \mathrm{m} \mathrm{d}^{-1}$ in fuel-exposed individuals and $6.7 \mu \mathrm{m} \mathrm{d}^{-1}$ in control fish. The comparison of lipid energy reserves gave further evidence of the poor energetic condition of fuel-exposed sole. After 6 month under semi-natural conditions mean triacylglycerols to sterols ratio was 2.3 in the control group but only 0.06 in the fuel-exposed group.

The ability of fish to sustain high level of activity is tightly linked to their ability to maintain appropriate internal flow of matter and energy (Nakanishi and Itazawa, 1974). Therefore, functional impairments affecting the gills or the cardiovascular system are likely to have serious consequences in this regard. We have no direct evidence for altered cardiorespiratory disturbance in contaminated individuals. However, in the parallel study mentioned above, Claireaux et al. (2004) reported that $83 \%$ of fuelexposed sole displayed histomorphological alterations of the gill epithelium. In particular, we observed that the respiratory epithelium on the secondary lamellae had completely disappeared. The functional consequences of these histological disturbances are difficult to establish but we can hypothesise that reduced metabolic performance in fuel exposed sole are related to these alterations of gill tissues. Stephens (2000) also reported that in juvenile turbot exposed to $10 \%$ oil for three weeks, approximately $50 \%$ of the gill lamellae were fused at their tips and resulted in impaired respiratory and ionoregulatory processes. Fusion of gill lamellae tips was also observed in rainbow trout exposed to $1 / 5000$ emulsion of crude oil (Engelhardt et al., 1981). Yellow sole (Pleuronectes asper) and rock sole (Pleuronectes bilineatus) exposed to oil also displayed alterations of the gill tissue (Moles and Norcross, 1998).

As mentioned above, impaired cardiovascular function may also have contributed to the lower AMR in contaminated fish. Experimental data proving a causal relationship between fuel exposure and impaired cardiovascular performance in fish are scarce. However, reduced routine heart rates in fish exposed to petroleum hydrocarbon have been reported in herring embryos (Clupea harengus; Middaugh et al., 1998), zebrafish (Danio rerio; Henry et al., 1997), and mummichog (Fundulus heteroclitus; Anderson et al., 1977).

Metabolic scope is an integrated measure of the energy resources that an animal can mobilise for routine activities in a given set of environmental and physiological conditions. High metabolic scope is believed to reduce the probability of conflicting energetic demand between physiological/behavioural processes and thereby it is believed to have positive repercussions upon the probability of survival (Priede, 1985; Evans, 1990). In the present case, the $30 \%$ reduction in scope for activity in fuelexposed fish must be viewed as a loss in animals' energetic flexibility. Consequently, in situations associated with high metabolic demand, contaminated juveniles are more likely to be faced with energy budgeting conflicts. As confirmed by the mesocosms experiment discussed above, such situations are generally resolved at the expense of both somatic and gonadic growth (Neill et al., 1994; Claireaux et al., 2004) and eventually result in increased mortality.

The determination of the critical water oxygen content illustrates further the limited ability of contaminated fish to cope with environmental challenges. The $\mathrm{O}_{2 \text { crit }}$ is the minimal environmental $\mathrm{O}_{2}$ level required to sustain SMR. The critical oxygen concentration of control, uncontaminated fish was $2.5 \mathrm{mg} \mathrm{O}_{2} \mathrm{I}^{-1}$. In contaminated fish, on the other hand, minimal oxygen requirement were increased by $64 \%, \mathrm{O}_{2 \text { crit }}$ reaching $4.1 \mathrm{mg} \mathrm{O}_{2} \mathrm{I}^{-1}$. Since SMR values in contaminated and control fish were comparable, this inability to sustain SMR in the face of reduced oxygen availability suggests that contaminated fish are less able to extract oxygen from the environment and/or to transport it to the various organs and functions. The former explanation would be consistent with histomorphological alterations to the gills, leading to reduced oxygen diffusion across the respiratory epithelium and into the blood (Claireaux et al., 2004). With regard to the latter, data available in the literature suggest that cardiac dysfunctions are likely but specifically dedicated studies are required to clarify this point.

Loss of functional integrity and related deficit of adaptive flexibility at the individual level can be interpreted, at the population level, in terms of probability of mortality and production e.g., growth or 
recruitment (Priede 1985; Neill et al., 1994). Data from fisheries surveys support this view and suggest that sole population from the Bay of Biscay may have been impacted by the ERIKA oil spill. Figure 3 shows the evolution of the number of juvenile sole of the age class 2 over the last 20 years in ICES divisions VIIlabd. The causal relationship linking the oil spill to the relative failure of the cohort which was present on the nurseries at the time is difficult to establish. Nonetheless, our experimental results are consistent with these field observations to suggest that the year class 1999 probably experienced impaired adaptive ability resulting from the contaminated environment.

\section{ACKNOWLEDGEMENTS}

We would like to thank Dr D.J. McKenzie for his comments while preparing this manuscript. We would also like to thank G. Guillou, M. Guillaut, P. Pineau, D. Leguay, M. Prineau, and H. Chartois for their technical assistance as well as C. Couturier for her help with the data analysis. We wish to acknowledge the help of the crew of the R/V "Gwen Drez", Y. Desaunay (Ifremer) and J.-M. Arruabarrena who kindly collected the fish. The current research was funded by "Ministère Français de l'Écologie et du Développement Durable" as part of the program "Suivi des conséquences écologiques et écotoxicologiques de la marée noire due au naufrage de l'Erika". The support of the scientific committee in charge of the program is sincerely acknowledged as well as the help of the "Centre de Documentation de Recherche et d'Expérimentation sur les pollutions accidentelles des Eaux". All experimental procedures in this work comply with the current laws in France. 


\section{REFERENCES}

Anderson J.W., Dixit D.B., Ward G.S., Foster R.S., 1977. Effects of petroleum hydrocarbons on the rate of heart beat and hatching success of estuarine fish embryos. In: Physiological responses of marine biota to pollutants. (eds Vernberg F.J., Calabrese A., Thurberg F.P., Vernberg W.B.) Academic press, INC New York London.

Bordenave S., Jézéquel R., Fourçans, A., Budzinski H., Merlin F.X., Fourel T., Goñi-Urriza M., Guyoneaud, R., Grimaud R., Caumette P., Duran R., 2004. Degradation of the "Erika" oil. Aquat. Living Resour. 17, 261-267.

Budzinski H., Mazéas O., Tronczynski J., Désaunay, Y., Bocquené, G., Claireaux, G., 2004. Link between exposure of fish (Solea solea) to PAHs and metabolites: Application to the "Erika" oil spill. Aquat. Living Resour. 17, 329-334.

Claireaux G., Désaunay Y., Akcha F., Aupérin B., Bocquené G., Budzinski H., Cravedi J.P., Davoodi F., Galois R., Gilliers C., Goanvec C., Guérault D., Imbert N., Mazéas O., Nonnotte G., Nonnotte L., Patrick Prunet P., Sébert P., Vettier A., 2004. Influence of oil exposure on the physiology and ecology of the common sole Solea solea: Experimental and field approaches. Aquatic Living Resources 17, 335-351.

Duthie G.G., 1982. The respiratory metabolism of temperature-adapted flatfish at rest and during swimming activity and the use of anaerobic metabolism at moderate swimming speed. Journal of Experimental Biology 97, 359-373.

Engelhardt F.R., Wong M.P., Duey M.E., 1981. Hydromineral balance and gill morphology in rainbow trout Salmo gairdneri acclimated to freshwater and seawater as affected by petroleum exposure. Aquatic Toxicology 1, 175-186.

Evans D.O., 1990. Metabolic thermal compensation by rainbow trout: Effect on standard metabolic rate and potential usable power. Transactions of the American Fisheries Society 119, 585-600.

Fry F.E., 1947. Effect of the environment on animal activity. University Toronto Studies, Biological Series 55, 1-62.

Fry F.E., 1971. The effect of environmental factors on the physiology of fish. In Hoar and Randall. Fish physiology, VI. Academic press., N.Y., S.Francisco, London., 1-98.

Jobling M., 1993. Bioenergetics: feed intake and energy partitioning. In: Rankin, J.C., Jensen F.B. (Eds), Fish Ecophysiology. Chapman and Hall, London, pp. 1-44.

Henry T.R., Spitsbergen J.M., Hornung M.W., Abent C.C., Peterson R.E., 1997. Early life stage toxicity of 2,3,7,8-tetrachlorodibenzo-p-dioxin in Zebrafish (Danio rerio). Toxicology and Applied Pharmacology 142, 56-98.

Kerr S.R., 1990. The Fry paradigm: its significance for contemporary ecology Transactions of the American Fisheries Society 119, 779-785.

Koutsikopoulos C., Désaunay Y., Dorel D., Marchand J., 1989. The role of coastal areas in the life history of sole (Solea solea) in the bay of Biscay. pp 567 575. In: J. D. Ros (ed) Topics in Marine Biology, Proc $22^{\text {nd }}$ EMBS, Scient, Mar.53.

Léauté J.P., Caill-Milly N., 2003. Les petites pêches côtières et estuariennes françaises du sud du golfe de Gascogne. Extrait du rapport final du contrat PECOSUDE EC/DG Fish (DC XIV) No. 99/024, Ifremer, DRV/RH/DT/03-01.

Lefrançois C., Claireaux G., 2003. Influence of ambient oxygenation and temperature on metabolic scope and scope for heart rate in the common sole Solea solea. Marine Ecology Progress Series 259, 273-284.

Mallekh R., Lagardère J.P., 2002. Effect of temperature and dissolved oxygen concentration on the metabolic rate of the turbot and the relationship between metabolic scope and feeding demand. Journal of Fish Biology 60, 1105-1115.

Mazéas L., Budzinski H., 2001, Improved accuracy of GC-MS quantification of aliphatic and aromatic hydrocarbons in marine sediments and petroleums. Validation on reference matrices and application to the Erika oil spill. Intern. J. Environ. Anal. Chem. 82, 157-173.

Middaugh D.P., Shelton M.E., McKenney C.L., Cherr G.N., Chapman P.J., Courtney L.A., 1998. Preliminary observations on responses of embryonic and larval Pacific herring, Clupea pallasi, to neutral fraction biodegradation products of weathered Alaska north slope oil. Arch. Environ. Contam. Toxicol. 34, 188-196.

Moles A., Norcross B.L., 1998. Effects of oil-laden sediments on growth and health of juvenile flatfishes. Canadian Journal of Fisheries and Aquatic Sciences 55 (3), 605-610.

Nakanishi T., Itazawa Y., 1974. Effect of hypoxia on the breathing rate, heart rate and rate of oxygen consumption in fishes. Report of fishery research laboratory, Kyushu University, 2, 41-52. 
Neill W.H., Miller J.M., Van Der Veer H.K., Winemiller K.O., 1994. Ecophysiology of marine fish recruitment: A conceptual framework for understanding interannual variability. Netherland Journal of Sea Research 32, 135-152.

Oudot J., 2000. Biodegradability of Erika fuel oil. C. R. Acad. Sci. III, Sci. Vie 323, 945-950.

Priede I.G., 1985. Metabolic scope in fish. In: Fish energetics: new perspectives (eds Tyler, P. and Calow P.). Croom Helm, London, 33-64.

Stephens S.M., Frankling S.C., Stagg R.M., Brown J.A., 2000. Sub-lethal effects of exposure of juvenile turbut to oil produced water. Marine Pollution Bulletin 40, 928-937.

Tronczynski J., Munschy C., Moisan K., Guiot N., Truquet I., Olivier N.,Men S., Furaut A., 2004, Contamination of the Bay of Biscay by polycyclic aromatic hydrocarbons (PAHs) following the T/V "Erika" oil spill. Aquat. Living Resour. 17, 243-259.

Van Den Thillart G., Dalla Via J., Vitali G., Cortesi P., 1994. Influence of long-term hypoxia exposure on the energy metabolism of Solea solea. I. Critical $\mathrm{O}_{2}$ levels for aerobic and anaerobic metabolism. Marine Ecology Progress Series 104, 109-117.

Van der Veer H.W., Berghahn R., Miller J.M., Rijnsdorp A.D., 2000. Recruitment in flatfish, with special emphasis on North Atlantic species: Progress made by the Flatfish Symposia. ICES Journal of Marine Sciences. 57, 202-215.

Webber D.M., Boutilier R.G., Kerr S.R., 1998. Cardiac output as a predictor of metabolic rate in cod Gadus morhua. Journal of Experimental Biology 201, 2779-2789. 
Table 1. Values of the parameters estimated for the modelling of the $M O_{2}=a \log \mathrm{O}_{2}+b$.

\begin{tabular}{ccc}
\hline Parameters & Control & Contaminated \\
\hline a & 16.98 & 12.18 \\
b & 23.64 & 14.47 \\
\hline
\end{tabular}


Fig. 1. Standard (SMR) and active (AMR) metabolic rates in control and 5-day fuel exposed fish. For a given fish group the difference between SMR and AMR corresponds to the aerobic metabolic scope.

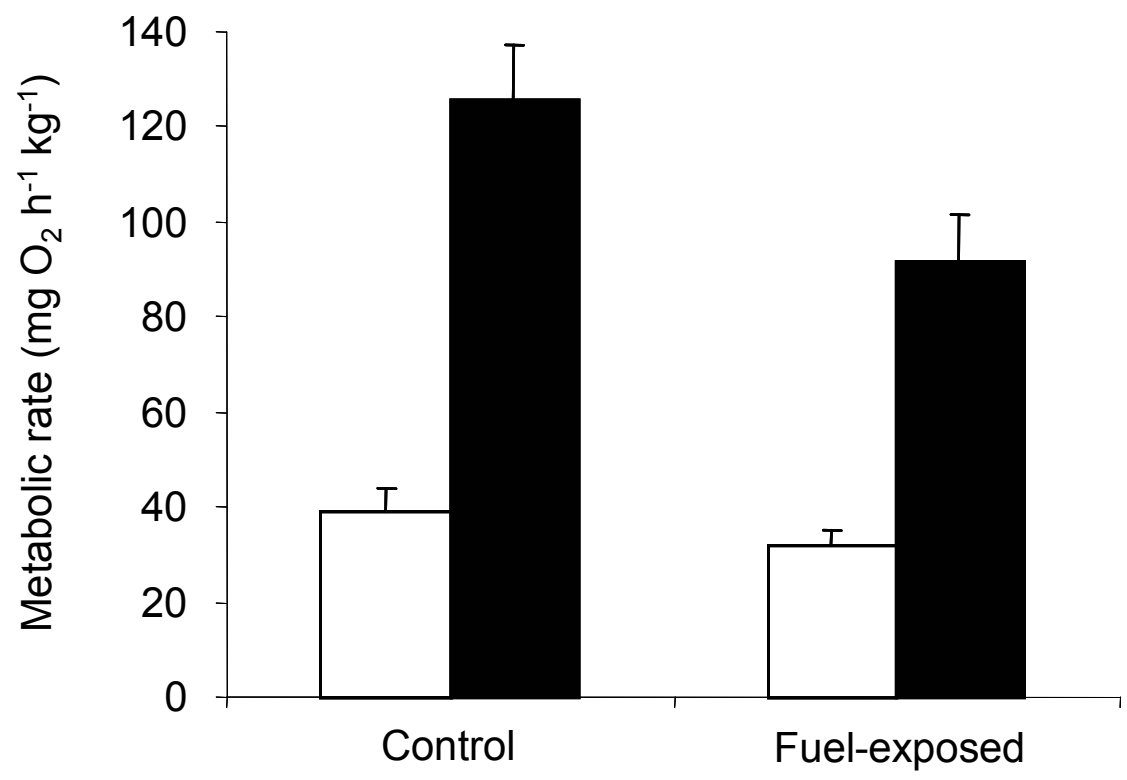


Fig. 2. Effect of a 5-day fuel exposure on metabolism. A: Control fish $(n=10)$; B: fuel-exposed fish. Diamonds: routine oxygen consumption. arrows: critical water oxygen concentration. Solid line: standard metabolic rate. Dotted lines: \pm SEM.
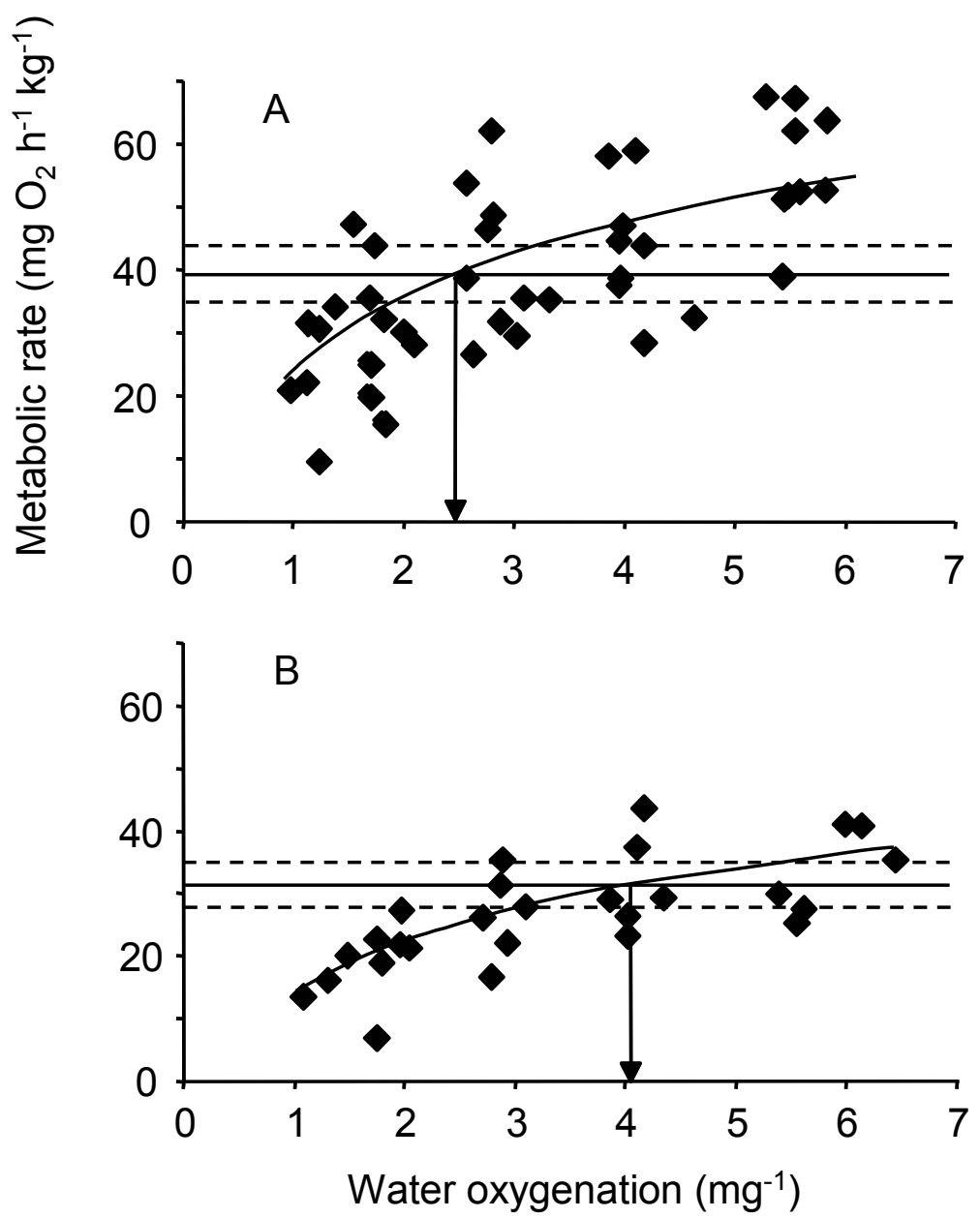
Fig. 3. The recruitment of group-2 juvenile sole in the Bay of Biscay (Division VIIIabd). Note that the recruitment of the cohort born in 1999 (grey bar) is approximately $40 \%$ lower than that of the preceding and following 2 years. Data from ICES Advisory Committee on Fishery Management (http://www.ices.dk).

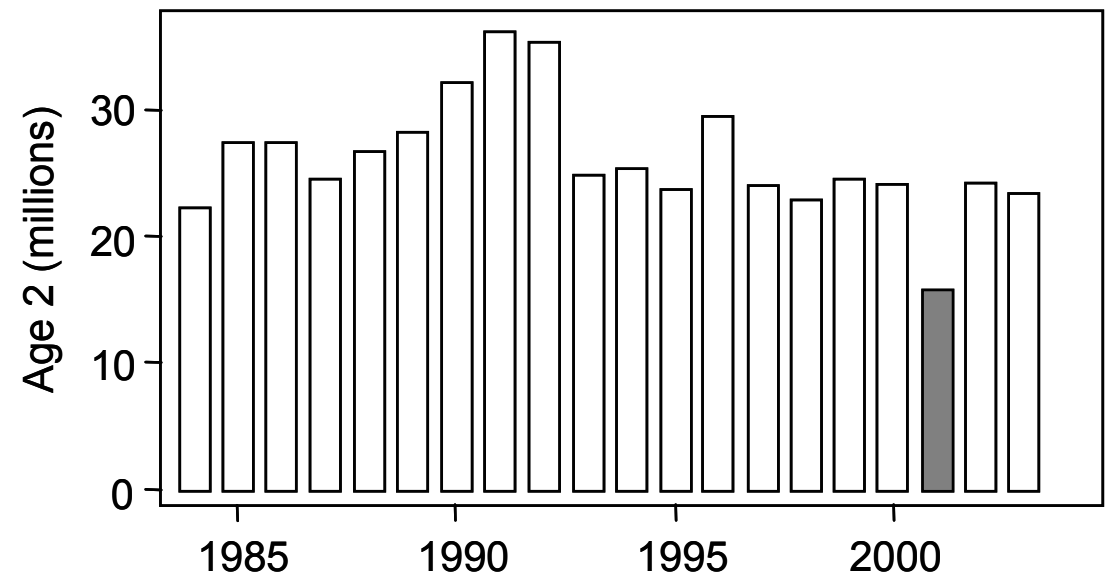

